\title{
G-CSF and/or M-CSF accelerate differentiation of bone marrow cells into endothelial progenitor cells in vitro
}

\author{
YUMING ZHANG $^{1,4}$, YASUSHI ADACHI ${ }^{12,3}$, MASAYOSHI IWASAKI ${ }^{1}$, KEIZO MINAMINO $^{1}$, \\ YASUHIRO SUZUKI ${ }^{1}$, KEIJI NAKANO $^{1}$, YASUSHI KOIKE ${ }^{1}$, HIROMI MUKAIDE $^{1}$, \\ AKIO SHIGEMATSU ${ }^{1}$, NAOKO KIRIYAMA ${ }^{1}$, CHUNFU LI $^{4}$ and SUSUMU IKEHARA ${ }^{1,2,3}$
}

${ }^{1}$ First Department of Pathology, ${ }^{2}$ Regeneration Research Center for Intractable Diseases, ${ }^{3}$ Center for Cancer Therapy, Kansai Medical University, Moriguchi, Japan; ${ }^{4}$ Department of Pediatrics, Nanfang Hospital, Guangzhou, China

Received January 10, 2006; Accepted February 27, 2006

\begin{abstract}
It has been reported that granulocyte-colony stimulating factor (G-CSF) and granulocyte-macrophagecolony stimulating factor (GM-CSF) can mobilize endothelial progenitor cells (EPCs) in bone marrow cells (BMCs) into peripheral blood (PB) in vivo. Previously, we also reported that macrophage-colony stimulating factor (M-CSF) can mobilize EPCs into PB, which results in the rapid recovery of blood flow in induced-ischemia limbs by augmenting the number of intramuscular capillaries in vivo. In the present study, we demonstrate that M-CSF and/or G-CSF can increase EPCs from lineage (CD3, B220, Gr-1, Mac-1, CD11c, Ter119, NK1.1 or CD31)-negative BMCs in vitro. Lineage-negative BMCs were cultured with or without M-CSF and/or G-CSF. Three days after culture with M-CSF and/or G-CSF, the number of $\mathrm{Flk}-1^{+} / \mathrm{CD}_{4} 5^{-}, \mathrm{Sca}-1^{+} / \mathrm{CD} 45^{-}, \mathrm{CD} 31^{+} / \mathrm{CD} 45^{-}$or $\mathrm{CD} 146^{+} / \mathrm{CD} 45^{-}$cells increased in comparison with no cytokines. When the cultured BMCs with or without G-CSF and/or M-CSF were intravenously injected into ischemiainduced hindlimbs of mice, the number of intramuscular capillaries in the ischemia-induced legs increased; BMCs cultured with G-CSF and/or M-CSF were more effective than those of cytokine non-treated BMCs. These results suggest that M-CSF and/or G-CSF can induce the differentiation of BMCs into EPCs, even in vitro.
\end{abstract}

\section{Introduction}

It has been reported that BMCs can differentiate into endothelial cells, and EPCs are present in the bone marrow (BM) and PB of animals and humans (1-5). Kalka et al

Correspondence to: Dr Susumu Ikehara, First Department of Pathology, Kansai Medical University, 10-15 Fumizono-cho, Moriguchi City 570-8506, Japan

E-mail: ikehara@takii.kmu.ac.jp

Key words: neovascularization, granulocyte-colony stimulating factor, macrophage-colony stimulating factor, endothelial progenitor cell reported that human peripheral blood mononuclear cell (PBMNC)-derived EPCs rescued induced-ischemia legs of nude mice from necrosis (4). Takeishi-Yuyama et al reported that an injection of autologous BM mononuclear cells (BM$\mathrm{MNCs}$ ) into the ischemic muscles of patients with arteriosclerosis induced the recovery of blood flow in their ischemic legs (5). Thus, BMCs and EPCs in PB are clinically used for the treatment of ischemic diseases of the limbs.

We previously reported that G-CSF and/or M-CSF can mobilize EPCs from BM, and the mobilized EPCs migrate to induced-ischemia muscles and differentiate into endothelial cells in blood vessels, resulting in the augmentation of blood flow in muscle (6).

G-SCF is known to accelerate the differentiation of bone marrow hematopoietic stem cells into granulocytes, and is clinically used for patients after chemotherapy and bone marrow transplantation (BMT) and also for patients with aplastic anemia $(7,8)$. In contrast, M-CSF is known to stimulate the differentiation of hematopoietic stem cells into monocytemacrophage lineage cells and augment the functions of monocyte-macrophage lineage cells $(9,10)$. However, several side effects of these cytokines have been reported: in G-CSF, thrombocytopenia and the exacerbation of inflammation; and in M-CSF, shock, fever and general fatigue (7). Therefore, if we can utilize EPCs for the treatment of ischemic diseases after their expansion in vitro, the side effects of the cytokines could be reduced.

In this study, we show that G-CSF and/or M-CSF can augment the number of EPCs from lineage (Lin)-negative BMCs in vitro, and these EPCs can differentiate into endothelial cells in vivo, followed by the augmentation of blood flow in the ischemia-induced leg.

\section{Materials and methods}

Animals. C57BL/6 (B6, H-2b) mice were purchased from Japan SLC (Hamamatsu, Japan). B6 mice carrying the eGFP transgene (eGFP B6 mice) were kindly donated by Dr Okabe (Osaka University, Osaka, Japan). All mice were maintained under specific pathogen-free conditions in our animal facility until use. All mice were used at 8-12 weeks of age for this experiment. 

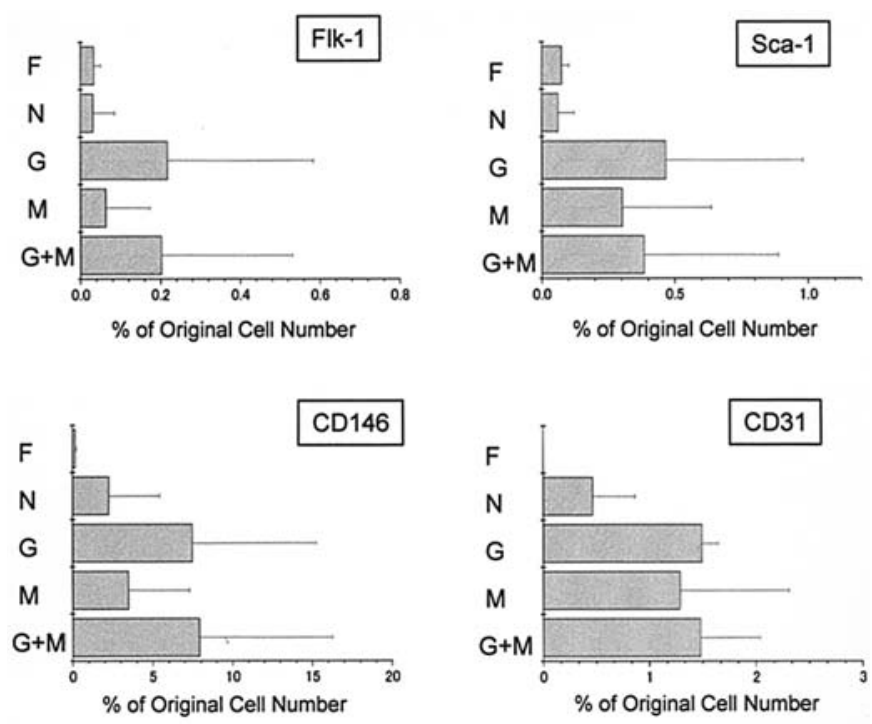

Figure 1. G-CSF and M-CSF augment the number of EPCs. Purified Linbone marrow cells (BMCs) were cultured with or without G-CSF (30 ng/ml) and/or M-CSF (30 ng/ml) for 3 days. The cells were harvested, counted, and stained with Cy5.5-labeled anti-CD45 and PE-labeled anti-CD146, anti-Sca-1, anti-CD31 or anti-Flk-1 Abs. The number of CD $45 / \mathrm{Sac}-1^{+}$cells, CD $45 / \mathrm{Flk}-1^{+}$ cells and $\mathrm{CD} 45 / \mathrm{CD} 31^{+}$cells was calculated with harvested cell number and percentages of indicated cells. The percentages of indicated cells to the original Lin- cells were calculated with cell number of the indicated cells and original cell numbers, using the following equation: (cell number of the indicated cells) x100/(original cell number). F, freshly isolated Lin-BMCs; G, Lin-BMCs cultured with G-CSF; M, Lin-BMCs cultured with M-CSF; and $\mathrm{G}+\mathrm{M}$, Lin-BMCs cultured with G-CSF plus M-CSF.

Antibodies. Biotin-conjugated rat anti-mouse monoclonal antibodies (Abs) against CD3, B220, Gr-1, CD11b, Ter119, CD31, NK1.1 and CD11c were purchased from PharMingen (San Diego, CA, USA). Streptavidin-conjugated magnetic beads (Dynabeads M-280 streptavidin) were from Dynal (Oslo, Norway). Phycoerythrin (PE)-coupled anti-CD31, anti-Flk1 and Sca-1 Abs were also from PharMingen, and PE coupled anti-endothelial cell marker (CD146) Ab and Tricolor (TC)-labeled anti-CD45 Ab were from Chemicon International (Temecula, CA, USA).

Cell preparation. BMCs were collected from the tibias and femurs of B6 or eGFP B6 mice and then rinsed and suspended in phosphate-buffered saline (PBS) containing 2\% heatinactivated fetal calf serum (FCS) (PBS-FCS). After centrifugation, the cells were incubated with a mixture of biotincoupled mAbs against CD3, B220, TER119, CD11c, CD11b, CD31, Gr-1 and NK1.1 for 30 min on ice, then washed twice with PBS-FCS, followed by incubation with streptavidinconjugated magnetic-beads (Dynabeads) to negatively enrich the Lin-BMCs. These cells were stained with PE-Cy5-labeled avidin (Dako, Glostrup, Denmark) to detect the residual lineage cells, and sorted using an Epics Altra ${ }^{\mathrm{TM}}$ cell sorter (Beckman-Coulter, Fullerton, CA, USA), to purify Lin-BMCs. These cells were cultured with or without M-CSF and/or G-CSF.

Culture of Lin-cells. The sorted cells were equally divided into 4 groups and cultured in a Biocoat endothelial cell growth environment (BD Biosciences, San Diego, CA, USA)

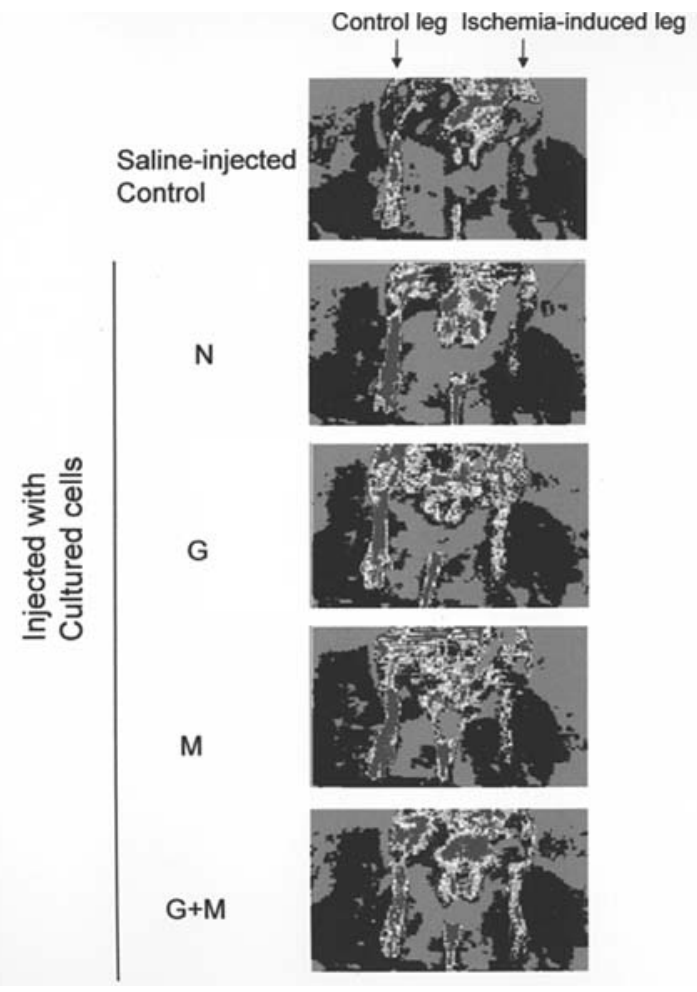

Figure 2. Injection of Lin-BMCs cultured with G-CSF and/or M-CSF is effective in improving the blood flow in ischemia-induced limbs. Purified Lin-bone marrow cells (BMCs) were cultured with or without G-CSF $(30 \mathrm{ng} / \mathrm{ml})$ and $/$ or M-CSF $(30 \mathrm{ng} / \mathrm{ml})$ for 2 days, and injected into mice in which hindlimb-ischemia had been induced. Three days after the injection, the blood flow in the legs was examined by a laser Doppler perfusion image analyzer.

on a 30-mm collagen type I-coated dish (BD Biosciences) supplemented with or without M-CSF (30 ng/ml) and/or G-CSF (30 ng/ml). The four groups were as follows: i) culture without cytokine; ii) culture with G-CSF; iii) culture with M-CSF; and iv) culture with G-CSF and M-CSF. The cultured cells were harvested after 3-day culture, then stained with the indicated antibodies, and analyzed with a BD LSR (BD Biosciences).

Preparation of hindlimb ischemia. On day 0 , unilateral hindlimb ischemia was induced by resecting the right femoral arteries and veins of $\mathrm{B} 6$ mice, and the mice were then injected with cultured Lin-BMCs from eGFP B6 mice. Three days after surgery, the mice were sacrificed to study neovascularization. The skeletal muscles (bilateral gastrocnemius muscle) were isolated, embedded in OCT compound (Miles Scientific, Elkhardt, IN), and snap-frozen in liquid nitrogen.

Histological analyses. Histological analyses were performed as previously described $(11,12)$. Briefly, $2-\mu \mathrm{m}$ sections of frozen muscle were stained with PE-labeled anti-CD31 Ab (Caltag, Burlingame, CA) to detect blood vessels. They were then observed using a confocal laser microscope (Olympus, Tokyo, Japan).

Laser Doppler perfusion image. The hindlimbs of mice were shaved using a razor. The mice were anesthetized with $160 \mathrm{mg} / \mathrm{kg}$ pentobarbital, then fixed supine on a cork plate. 
Untreated leg
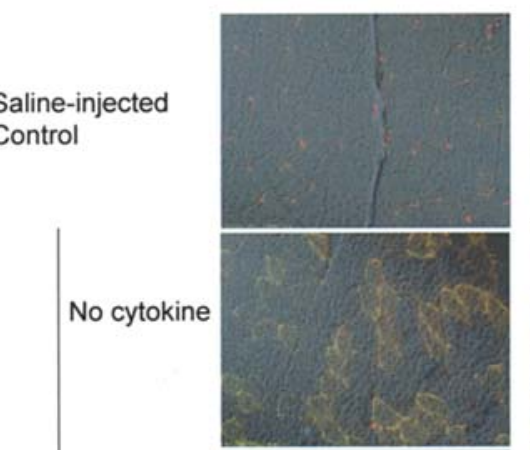

\section{G-CSF}
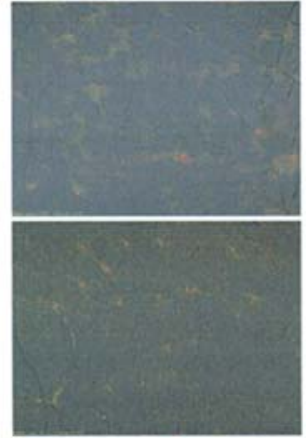

G-CSF



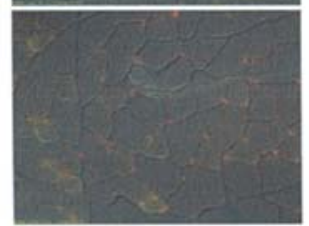

Ischemia-induced leg
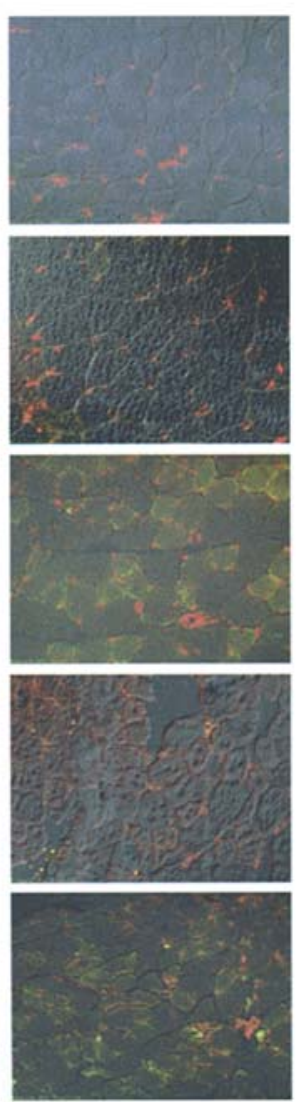

Figure 3. Injection of Lin-BMCs cultured with G-CSF and/or M-CSF augments the number of blood vessels in ischemia-induced limbs. Purified Lin-bone marrow cells (BMCs) were cultured with or without G-CSF $(30 \mathrm{ng} / \mathrm{ml})$ and/or M-CSF $(30 \mathrm{ng} / \mathrm{ml})$ for 2 days and injected into the mice in which hindlimb ischemia had been induced. Three days after injection, the mice were sacrificed, and muscles from induced-ischemia legs and contralateral control legs were obtained. Sections from the muscles were stained with PE-labeled anti-CD31 Ab and observed using a confocal microscopy.

We next measured the blood flow in the limbs using a laser Doppler perfusion image analyzer (Moor Instrument, Millwey, Devon, UK) as described previously (13).

\section{Results}

G-CSF and/or M-CSF augment the number of EPCs in vitro. We previously demonstrated that G-CSF and/or M-CSF can mobilize EPC into the PB from the BM, followed by the augmentation of neovascularization in ischemia-induced limbs in vivo (6). This encouraged us to analyze the effects of G-CSF and/or M-CSF on the augmentation of the number of EPCs in vitro. We cultured lineage-negative BMCs in a Biocoat endothelial cell growth environment with or without G-CSF and/or M-CSF. After 3-day culture, the cultured cells were analyzed for the markers of EPCs or endothelial cells. As shown in Fig. 1, either G-CSF or M-CSF augments the number of CD45-/CD146+ cells, CD45-/CD31+ cells, CD45\% Sca- $1^{+}$cells and CD45/Flk- $1^{+}$cells. Moreover, G-CSF plus $\mathrm{M}-\mathrm{CSF}$ have synergistic effects on the increase in number of these cells.
A.



B.

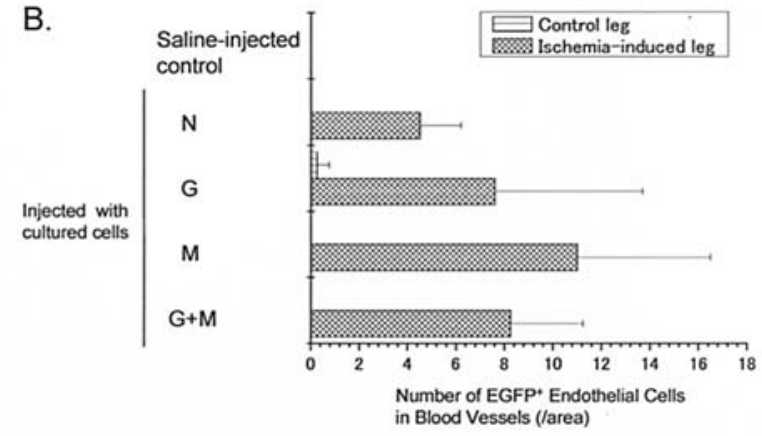

Figure 4. Injection of Lin-BMCs cultured with G-CSF and/or M-CSF can differentiate into endothelial cells in the blood vessels. Purified Lin-BMCs were cultured with or without G-CSF (30 ng/ml) and/or M-CSF (30 ng/ml) for 2 days and injected into the mice in which hindlimb-ischemia had been induced. Three days after injection, the mice were sacrificed, and muscles from induced-ischemia legs and contralateral control legs were obtained. Sections from the muscles were stained with PE-labeled anti-CD31 Ab and observed using a confocal microscopy. The number of blood vessels and eGFP+blood vessels was then counted. The means and standard deviations of vessel numbers in one field are shown.

EPCs after culture with G-CSF and/or M-CSF can induce rapid recovery of blood flow in ischemia-induced legs. We examined whether the EPCs induced from Lin-BMCs can really differentiate into endothelial cells in blood vessels and work functionally. Two-day cultured Lin-BMCs were injected into the vein of ischemia-induced hindlimbs of mice. Three days after injection, the blood flow of the ischemia-induced legs was examined using a laser Doppler perfusion image analyzer. As shown in Fig. 2, the mice that had been injected with the BMCs cultured with G-CSF and/or M-CSF showed a better recovery of blood flow than the mice injected with BMCs cultured without cytokines. We also examined the number of blood vessels in bilateral gastrocnemius muscles, as shown in Figs. 3 and 4. In the ischemia-induced muscle of mice injected with BMCs cultured with G-CSF and/or M-CSF, the number of blood vessels increased in comparison with that of mice injected with BMCs cultured without cytokines. Moreover, the cultured BMC-derived endothelial cells were detected in the ischemia-induced muscle in mice injected with cultured BMCs. The number of blood vessels induced from injected BMCs in the ischemia-induced muscles increased more in mice injected with BMCs cultured with G-CSF and/or $\mathrm{M}-\mathrm{CSF}$ than in mice injected with BMCs cultured without G-CSF and M-CSF. However, there was no significant difference in the number of blood vessels between the mice injected with BMCs cultured with G-CSF, M-CSF and G-CSF plus M-CSF. 


\section{Discussion}

In the present study, we demonstrated that G-CSF and/or M-CSF can accelerate the differentiation of BMCs into EPCs in vitro. G-CSF has been reported to be able to mobilize not only hematopoietic stem cells (HSCs), but also EPCs from the BM, and that EPCs contribute to the angiogenesis of tumors (14). M-CSF has been reported to be crucial for the differentiation of hematopoietic stem cells into monocytes and macrophages $(15,16)$. At present, these cytokines are clinically used to enhance hematopoiesis. G-CSF is used for: i) the mobilization of HSCs from donor BM into PB for the purpose of peripheral blood stem cell transplantation (PBSCT) (17-19); ii) the augmentation of WBC counts of patients suffering from severe infection and aplastic anemia (20-23); and iii) the acceleration of hematopoietic recovery after BMT and chemotherapy $(24,25)$. In contrast, M-CSF is clinically used not only for the acceleration of hematopoietic recovery after BMT but also for the augmentation of anti-fungal response after BMT $(26,27)$. Therefore, these cytokines can be expected to be safely used even after in vitro expansion.

We previously reported that M-CSF can mobilize EPCs and accelerate the neovascularization of ischemic limbs in vivo (6). Even in humans, it has been reported that G-CSF has some effects on neovascularization (28). Therefore, it is expected that the injection of these cytokines would clinically induce neovascularization of the ischemic tissues and organs. There are several reports indicating that EPCs are induced from embryonal stem (ES) cells and BMCs using several cytokines in vitro. Nishikawa et al have shown that ES cells can differentiate into both hematopoietic cells and endothelial cells (29). Kalka et al have also shown that BMCs can differentiate into EPCs, which can rescue the ischemia-induced legs from necrosis (4). Therefore, if we can expand EPCs from BMCs and transplant the EPCs into the ischemic organs, we can reduce the various side effects of these cytokines.

In this study, we have shown that G-CSF and/or M-CSF can augment the number of EPCs from BMCs in vitro. These results suggest the possibility of using in vitro-expanded EPCs by G-CSF and/or M-CSF in a clinical setting.

\section{Acknowledgements}

We thank Ms. Murakami-Shinkawa, Ms. Tokuyama and Ms. Miura for their expert technical assistance, and also $\mathrm{Mr}$. Eastwick-Field and Ms. Ando for the preparation of this manuscript. This study was supported by grants from the Haiteku Research Center of the Ministry of Education, a Grant-in-Aid for scientific research (B), 11470062; a Grantin-Aid for scientific research (Hoga), 16659107; Grant-in-Aid for scientific research on priority area (A), 10181225 and (A) 11162221; a grant from 'Millennium' of the Ministry of Education, Culture, Sports, Science and Technology, and a grant from the 'Scientific Frontier' program of the Ministry of Education, Culture, Sports, Science and Technology.

\section{References}

1. Asahara T, Murohara T, Sullivan A, Silver M, van der Zee R, Li T, Witzenbichler B, Schatteman G and Isner JM: Isolation of putative progenitor endothelial cells for angiogenesis. Science 275: 964-967, 1997.
2. Kamihata H, Matsubara H, Nishiue T, Fujiyama S, Amano K, Iba O, Imada T and Iwasaka T: Improvement of collateral perfusion and regional function by implantation of peripheral blood mononuclear cells into ischemic hibernating myocardium. Arterioscler Thromb Vasc Biol 22: 1804-1810, 2002.

3. Fujiyama S, Amano K, Uehira K, Yoshida M, Nishiwaki Y, Nozawa Y, Jin D, Takai S, Miyazaki M, Egashira K, Imada T, Iwasaka $\mathrm{T}$ and Matsubara $\mathrm{H}$ : Bone marrow monocyte lineage cells adhere on injured endothelium in a monocyte chemoattractant protein-1-dependent manner and accelerate reendothelialization as endothelial progenitor cells. Circ Res 93: 980-989, 2003.

4. Kalka C, Masuda H, Takahashi T, Kalka-Moll WM, Silver M, Kearney M, Li T, Isner JM and Asahara T: Transplantation of ex vivo expanded endothelial progenitor cells for therapeutic neovascularization. Proc Natl Acad Sci USA 97: 3422-3427, 2000.

5. Tateishi-Yuyama E, Matsubara H, Murohara T, Ikeda U, Shintani S, Masaki H, Amano K, Kishimoto Y, Yoshimoto K, Akashi H, Shimada K, Iwasaka T and Imaizumi T: Therapeutic Angiogenesis using Cell Transplantation (TACT) Study Investigators. Therapeutic angiogenesis for patients with limb ischaemia by autologous transplantation of bone-marrow cells: a pilot study and a randomised controlled trial. Lancet 360: 427-435, 2002.

6. Minamino K, Adachi Y, Okigaki M, Ito H, Togawa Y, Fujita K, Tomita M, Suzuki Y, Zhang Y, Iwasaki M, Nakano K, Koike Y, Matsubara H, Iwasaka T, Matsumura M and Ikehara S: Macrophage colony-stimulating factor (M-CSF) as well as granulocyte colony-stimulating factor (G-CSF) accelerates neovascularization. Stem Cells (In press).

7. Andreeff $\mathrm{M}$ and Welte K: Hematopoietic colony-stimulating factors. Semin Oncol 16: 211-229, 1989.

8. Tsuchiya M, Nomura H, Asano S, et al: Characterization of recombination human granulocyte-colony stimulating factor produced in mouse cells. EMBO J 6: 611-616, 1987.

9. Yanai N, Yamada M, Watanabe Y, et al: The granulopoietic effect of human urinary colony stimulating factor on normal and cyclophosphasmide treated mice. Exp Hematol 11: 1027-1036, 1983.

10. Kawasaki ES, Ladner MB, Wang AM, et al: Molecular cloning of a complementary DNA encoding human macrophage specific colony-stimulating factor (CSF-1). Science 230: 291-296, 1985.

11. Tomita M, Adachi Y, Yamada H, Takahashi K, Kiuchi K, Oyaizu H, Ikebukuro K, Kaneda H, Matsumura M and Ikehara S: Bone marrow-derived stem cells can differentiate into retinal cells in injured rat retina. Stem Cells 20: 279-283, 2002.

12. Tomita M, Yamada H, Adachi Y, Cui Y, Yamada E, Higuchi H, Minamino M, Suzuki Y, Matsumura M and Ikehara S: Choroidal neovascularization is provided from bone marrow cells. Stem Cells 22: 21-26, 2004.

13. Amano K, Okigaki M, Adachi Y, Fujiyama S, Mori Y, Kosaki A, Iwasaka T and Matsubara H: Mechanism for IL-1 beta-mediated neovascularization unmasked by IL-1 beta knock-out mice. J Mol Cell Cardiol 36: 469-480, 2004.

14. Natori T, Sata M, Washida M, Hirata Y, Nagai R and Makuuchi M: G-CSF stimulates angiogenesis and promotes tumor growth: potential contribution of bone marrow-derived endothelial progenitor cells. Biochem Biophys Res Commun 297: 1058-1061, 2002.

15. Wiktor-Jedrzejczak W, Ratajczak MZ, Ptasznik A, Sell KW, Ahmed-Ansari A and Ostertag W: CSF-1 deficiency in the op/op mouse has differential effects on macrophage populations and differentiation stages. Exp Hematol 20: 1004-1010, 1992.

16. Wing EJ, Ampel NM, Waheed A and Shadduck RK: Macrophage colony-stimulating factor (M-CSF) enhances the capacity of murine macrophages to secrete oxygen reduction products. J Immunol 135: 2052-2056, 1985.

17. Bensinger W, Singer J, Appelbaum F, Lilleby K, Longin K, Rowley S, Clarke E, Clift R, Hansen J, Shields T, Storb R, Weaver C, Weiden P and Buckner CD: Autologous transplantation with peripheral blood mononuclear cells collected after administration of recombinant granulocyte stimulating factor. Blood 81: 3158-3163, 1993.

18. Peters WP, Rosner G, Ross M, Vredenburgh J, Meisenberg B, Gilbert $\mathrm{C}$ and Kurtzberg J: Comparative effects of granulocytemacrophage colony-stimulating factor (GM-CSF) and granulocyte colony-stimulating factor (G-CSF) on priming peripheral blood progenitor cells for use with autologous bone marrow after high-dose chemotherapy. Blood 81: 1709-1719, 1993. 
19. Fu S and Liesveld J: Mobilization of hematopoietic stem cells. Blood Rev 14: 205-218, 2000.

20. Cheng AC, Stephens DP, Anstey NM and Currie BJ: Adjunctive granulocyte colony-stimulating factor for treatment of septic shock due to melioidosis. Clin Infect Dis 38: 32-37, 2004.

21. Killick SB and Marsh JC: Aplastic anaemia: management. Blood Rev 14: 157-171, 2000.

22. Matsuo Y, Iwanaga M, Mori H, Yoshida S, Kawaguchi Y, Yakata Y, Murata K, Nagai K, Jinnai I, Matsuo T, Kuriyama K and Tomonaga M: Recovery of hematopoietic progenitor cells in patients with severe aplastic anemia who obtained good clinical response with a combination therapy of immunosuppressive agents and recombinant human granulocyte colonystimulating factor. Int J Hematol 72: 37-43, 2000.

23. Ishikawa K, Tanaka H, Nakamori Y, Hosotsubo H, Ogura H, Nishino M, Shimazu T and Sugimoto H: Difference in the responses after administration of granulocyte colony-stimulating factor in septic patients with relative neutropenia. J Trauma 48: 814-825, 2000.

24. Dix SP and Gilmore CE: Cytokine therapy after bone marrow transplantation. Pharmacotherapy 16: 593-608, 1996.

25. Saarinen UM, Hovi L, Juvonen E, Riikonen P, Mottonen M and Makipernaa A: Granulocyte-colony-stimulating factor after allogeneic and autologous bone marrow transplantation in children. Med Pediatr Oncol 26: 380-386, 1996.
26. Masaoka T, Motoyoshi K, Takaku F, Kato S, Harada M, Kodera Y, Kanamaru A, Moriyama Y, Ohno R, Ohira M, et al: Administration of human urinary colony stimulating factor after bone marrow transplantation. Bone Marrow Transplant 3: 121-127, 1988.

27. Nemunaitis J, Shannon-Dorcy K, Appelbaum FR, Meyers J, Owens A, Day R, Ando D, O'Neill C, Buckner D and Singer J: Long-term follow-up of patients with invasive fungal disease who received adjunctive therapy with recombinant human macrophage colony-stimulating factor. Blood 82: 1422-1427, 1993.

28. Bussolino F, Ziche M, Wang JM, Alessi D, Morbidelli L, Cremona O, Bosia A, Marchisio PC and Mantovani A: In vitro and in vivo activation of endothelial cells by colony-stimulating factors. J Clin Invest 87: 986-995, 1991.

29. Nishikawa S-I, Nishikawa S, Hirashima M, Matsuyoshi N and Kodama H: Progressive lineage analysis by cell sorting and culture identifies FLK1+VE-cadherin+ cells at a diverging point of endothelial and hemopoietic lineages. Development 125: 1747-1757, 1998. 